\title{
Effect of milrinone on cardiac functions in patients undergoing coronary artery bypass graft: a meta-analysis of randomized clinical trials
}

This article was published in the following Dove Press journal:

Drug Design, Development and Therapy

24 December 2015

Number of times this article has been viewed

\section{Zhigang You* \\ Lin Huang* \\ Xiaoshu Cheng \\ Qinghua Wu \\ Xinghua Jiang \\ Yanqing $\mathrm{Wu}$}

Department of Cardiology, The Second Affiliated Hospital of Nanchang University, Nanchang, Jiangxi, People's Republic of China

*These authors contributed equally to this work
Correspondence: Zhigang You Department of Cardiology, The Second Affiliated Hospital of Nanchang University, No I Min De Road, Nanchang, Jiangxi 330006, People's Republic of China Tel +86 79186297276

Email youzhigang163@I63.com
Background and aim: Inotropes are commonly used to treat myocardial dysfunction, which is the major complication after coronary artery bypass graft (CABG). Milrinone, a phosphodiesterase 3 inhibitor, is one of these inotropes. Recently, a number of clinical studies have been carried out to evaluate the effects of milrinone on cardiac function in patients with low ventricular ejection fraction undergoing CABG. However, it has been inconclusive because of the inconsistent results. In addition, some studies found that milrinone increased the incidence of postoperative atrial arrhythmias and did not show any long-term beneficial effects on survival. Therefore, it is very important to perform a meta-analysis to summarize the results so as to determine the clinical efficacy and safety of milrinone.

Method: Several databases and websites for clinical trials were searched until October 2015 for prospective clinical studies comparing milrinone versus placebo on cardiac functions in patients undergoing CAGB.

Results: Four articles were identified by our search strategy. 1) Milrinone decreased incidence of myocardial ischemia and myocardial infarction ( $15.6 \%$ versus $44.4 \%$; $4.7 \%$ versus $18 \%$ in milrinone and control group, respectively). 2) Milrinone decreased duration of inotropic support (95\% confidence interval [CI]: -6.52 to $-1.68 ; P=0.0009)$ and mechanical ventilation (h) support ( $95 \% \mathrm{CI}-5.00$ to $-0.69 ; P=0.010$ ), but did not decrease the requirement for intra-aortic balloon pump or inotropic support $(P>0.05)$. 3) Milrinone did not decrease the overall mortality or morbidity, intensive care unit stay $(P>0.05)$.

Conclusion: Perioperative continuous infusion of milrinone is effective to lower incidence of myocardial ischemia and myocardial infarction in patients post-CABG, but it was unable to improve the overall morbidity and mortality or decreased duration of intensive care unit stay. The available sample size is small; therefore, future studies should be directed toward a better understanding of the benefit of milrinone to $\mathrm{CABG}$ patients.

Keywords: inotropic support, intra-aortic balloon pump, cardiac function, clinical trial, meta-analysis

\section{Introduction}

Myocardial dysfunctions, myocardial ischemia, and infarction are major complications after coronary artery bypass graft $(\mathrm{CABG})$ that needs inotropic support. ${ }^{1-3}$ Currently, there are three main treatment methods for these complications which include the following: 1) optimization of loading conditions; 2) inotropic support to increase myocardial contraction; and 3) mechanical support. Milrinone is a phosphodiesterase 3 inhibitor, which provides an alternative means of inotropic support via non- $\beta 1$-adrenergic pathways and vasodilatation. ${ }^{4-5}$ It also improves hemodynamic parameters and increases blood flow of the grafted internal mammary arteries as well 
as middle cerebral arteries during CABG. ${ }^{6}$ Previous studies indicated that milrinone is valuable in cardiac surgery by facilitating weaning from cardiopulmonary bypass. ${ }^{7-8}$

In recent years, a number of clinical studies have been carried out to evaluate the effects of milrinone on cardiac function in patients with low ventricular ejection fraction (LVEF) undergoing CABG. Milrinone may reduce the incidence of postoperative myocardial ischemia and infarction in patients with impaired left ventricular function undergoing CABG surgery. The results reported by Jebeli et al ${ }^{9}$ suggest that perioperative administration of milrinone in patients undergoing on-pump CABG, especially those with LVEF, is beneficial. Hadadzadeh et $\mathrm{al}^{10}$ reported that administration of milrinone in patients undergoing off-pump CABG with LVEF is useful and effective. ${ }^{10}$

There are a few studies evaluating the effects of milrinone on cardiac function in patients with low output syndrome who undergo $\mathrm{CABG}$, which have reported diverse results. In this manuscript, we performed a meta-analysis to summarize the results of these clinical trials so as to determine the clinical efficacy and safety of milrinone, in terms of intra-aortic balloon pump (IABP), inotropic support requirement, myocardial ischemia, myocardial infarction, duration of inotropic support, duration of intensive care unit (ICU) stay, mortality, and morbidity rate. The results of this meta-analysis will provide evidence-based information on administration of milrinone in patients undergoing CABG with LVEF.

\section{Methods}

\section{Search strategy}

References for this meta-analysis were obtained from PubMed and EMBASE searches of literature published until October 2015 and websites for clinical trials including http://www.clinicaltrials.gov/, using the key words "milrinone", "CABG", "clinical trial", and "cardiac function". Eligible studies were selected based on the following criteria: 1) study design: double-blind, placebo control, and randomized clinical trials; 2) subjects: eligible patients underwent $\mathrm{CABG}$; 3 ) interventions: patients received milrinone or placebo/nesiritide. The primary outcomes included requiring of IABP, inotropic support, incidence of myocardial ischemia and myocardial infarction. The secondary outcomes were duration of inotropic support, duration of ICU stay, and mortality and morbidity rate. If these inclusion criteria were not met, the studies were excluded from the analysis. All authors independently conducted study selection based on these criteria. Any discrepancy was resolved by group discussion of all authors.

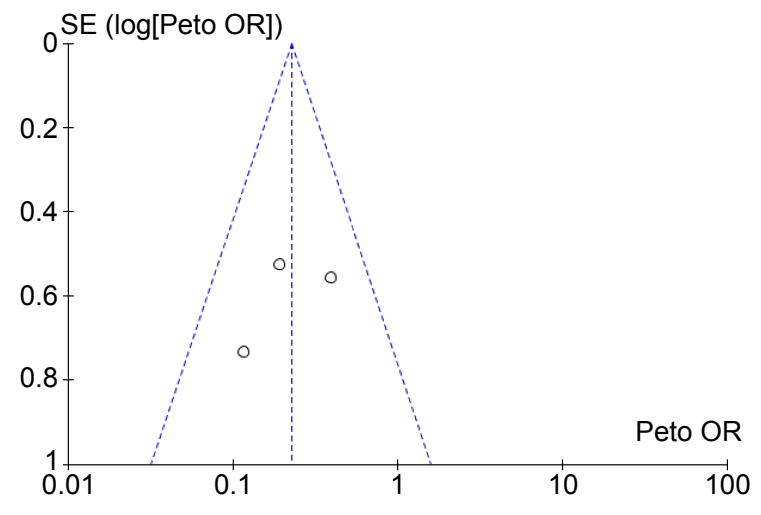

Figure I Funnel plot comparing the requirement of intra-aortic balloon pump (\%) between milrinone group and control/nesiritide group. Abbreviations: OR, odds ratio; SE, standard error.

\section{Data collection and statistical analysis}

The following information was extracted from selected studies: authors, publication year, study design, number of patients analyzed, treatment regimen, and primary and secondary outcomes. The meta-analyses were performed using the Review Manager, version 5.1.0 (Cochrane Collaboration, Oxford, UK). Dichotomous outcomes were presented as an event with a 95\% confidence interval (CI). The presence of heterogeneity across trials was also evaluated, with $R^{2}>50 \%$ indicating a substantial heterogeneity, where a random-effects model was used. In the case of $P^{2}<50 \%$, which indicates no significant heterogeneity, a fixed-effects model was used, $P$-value $<0.05$ was considered statistically significant. Peto-statistical models were used for the meta-analysis. The publication bias was assessed by funnel plot (Figure 1), which did not show any evidence of publication bias.

\section{Results}

\section{Identification of relevant studies}

A total of 53 published articles evaluated the effect of milrinone on cardiac functions in patients with post-CABG. Finally, only four articles were identified by our search strategy, which were double-blinded, placebo-controlled trials. A flow chart of study selection is shown in Figure 2. However, for some end points in final meta-analysis, we only used two to three available clinical trials, which provided those results.

1. IABP: 75 patients in each group who received milrinone or placebo were included in the statistical analysis. There was no significant difference between the two groups requiring of IABP. Four out of 75 patients (5.3\%) in the milrinone group versus eleven out of 75 patients $(14.7 \%)$ in the control group ( $P=0.06$; Figure $3 \mathrm{~A})$.

2. Inotropic support requirement: Similar result was observed in two groups. A 62 out of 106 patients (58.5\%) 


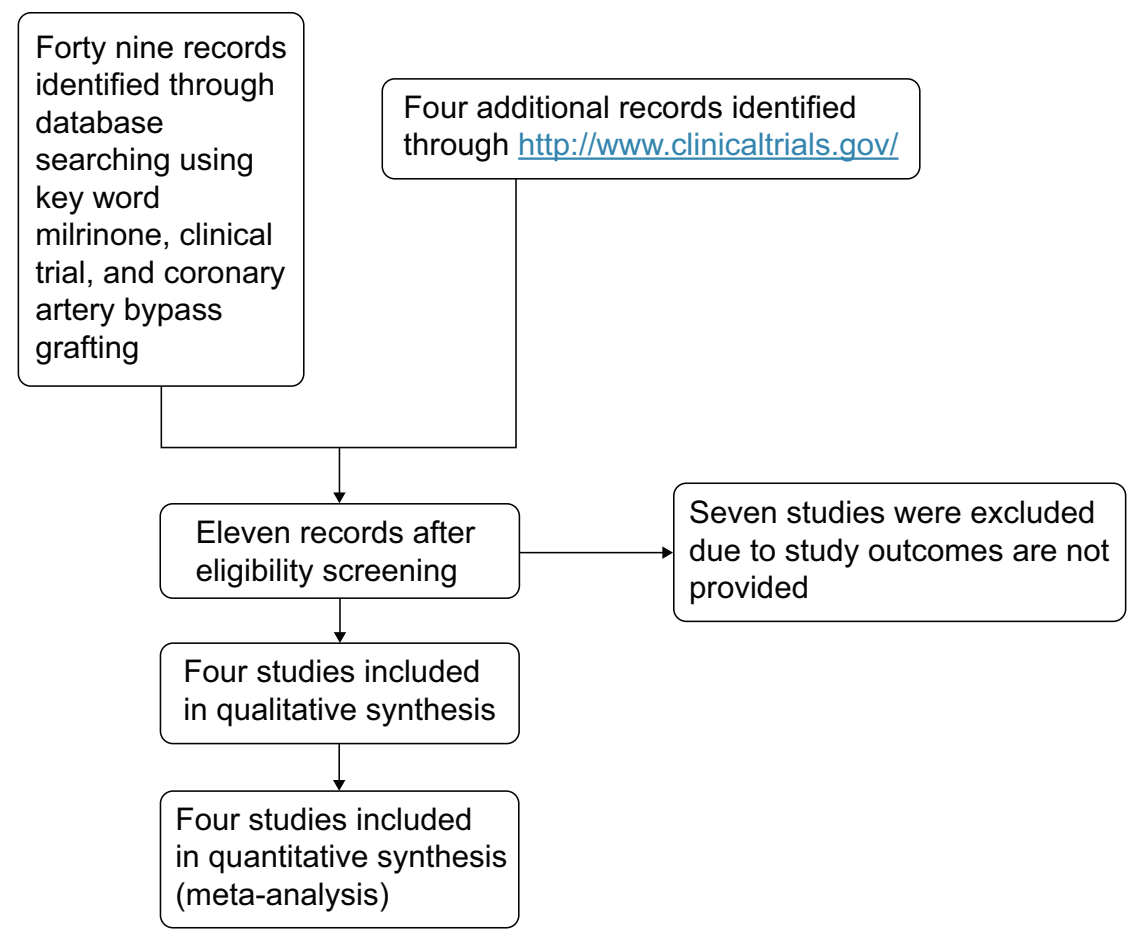

Figure 2 Flow diagram of study selection.

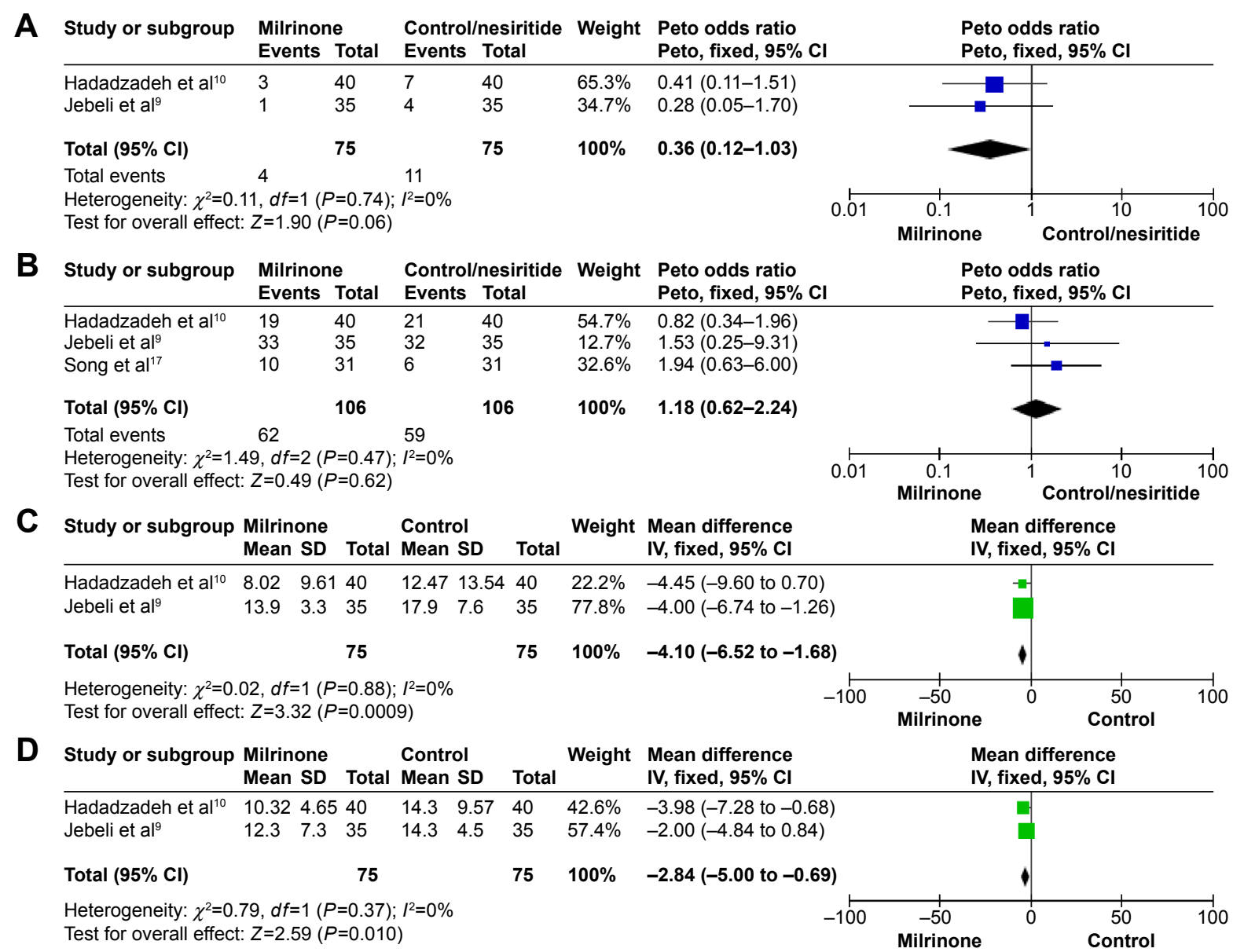

Figure 3 Forest plots comparing between milrinone group and placebo/nesiritide group the (A) requirement of intra-aortic balloon pump (\%); (B) inotropic support requirement; (C) duration of inotropic support; (D) duration of mechanical ventilation support.

Abbreviation: $\mathrm{Cl}$, confidence interval. 


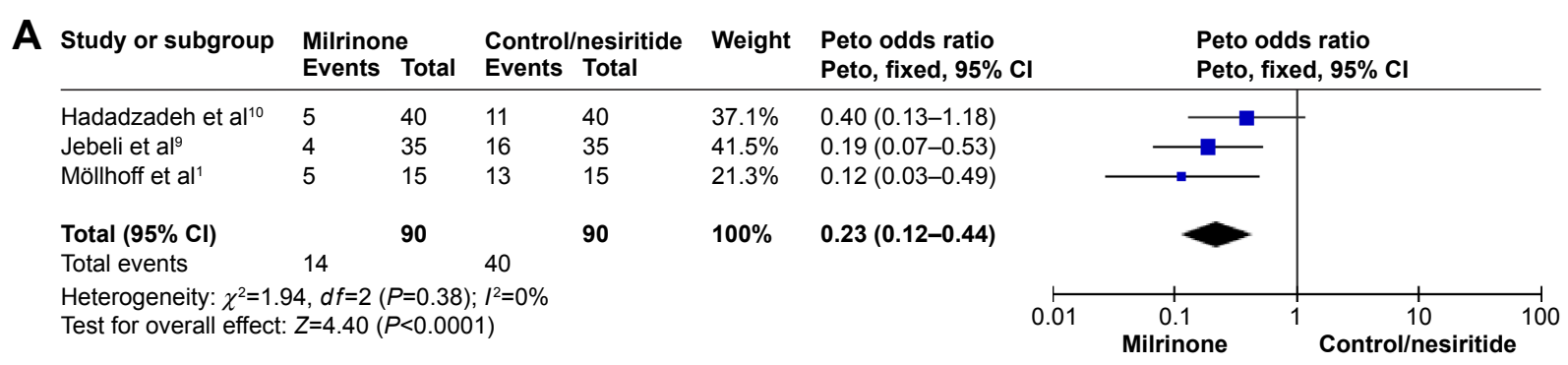

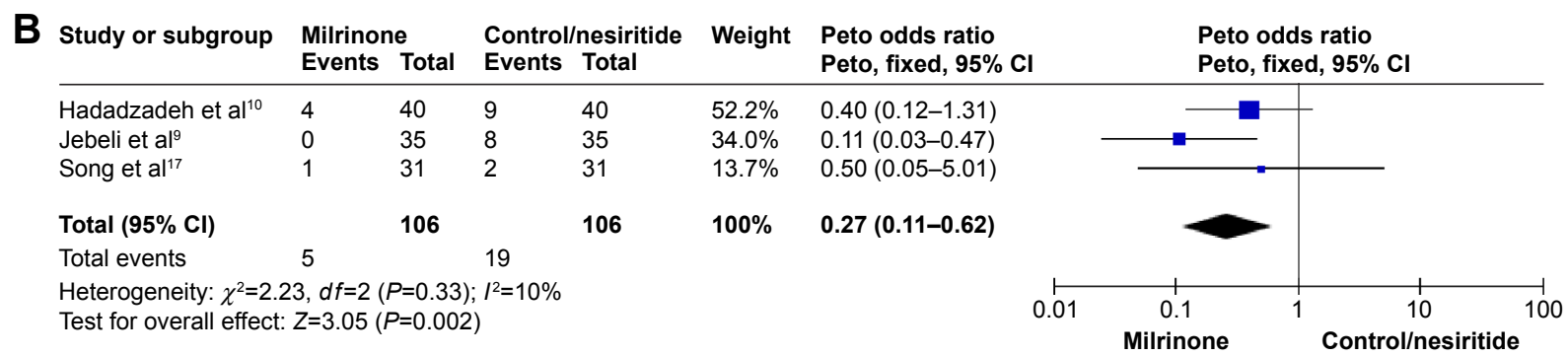

Figure 4 Forest plots comparing incidence of post-CABG complications between milrinone group and placebo/nesiritide group in (A) myocardial ischemia; (B) myocardial infarction.

Abbreviations: CABG, coronary artery bypass graft; $\mathrm{Cl}$, confidence interval.

in milrinone group versus 59 out of 106 patients $(55.7 \%)$ in control group who required inotropic support $(P=0.62$; Figure 3B).

3. Duration of inotropic support (h): significant difference was observed in duration of inotropic support between milrinone and control group (risk ratio [RR] $-4.10 ; 95 \%$ CI: -6.52 to $-1.68 ; P=0.0009$; Figure $3 \mathrm{C}$ ).

4. Duration of mechanical ventilation (h): significant difference was observed in duration of inotropic support between milrinone and control group (RR $-2.84 ; 95 \%$ CI: -5.00 to $-0.69 ; P=0.010$; Figure $3 \mathrm{D})$.

5. Incidence of myocardial ischemia: 90 patients in each milrinone group and placebo group were analyzed for the incidence of myocardial ischemia. Significant difference was observed between milrinone and control group: 14 out of 90 patients $(15.6 \%)$ in milrinone group had myocardial ischemia 24 hours after $\mathrm{CABG}$, in contrast 40 out of 90 patients $(44.4 \%)$ had it in control group, $<0.0001$ (Figure 4A).
6. Incidence of myocardial infarction: significant difference was observed in incidence of myocardial infarction between two groups. In milrinone group, five out of 106 patients $(4.7 \%)$ had myocardial infarction 24 hours after CABG versus 19 out of 106 patients (18\%) who had it in control group, $P=0.002$ (Figure 4B).

7. ICU stay: no statistical difference was identified in ICU stay (RR -0.16 ; $95 \% \mathrm{CI}$ : -0.52 to $0.19 ; P=0.37$ ); between milrinone and control treatment (Figure 5).

8. Mortality and morbidity: A total of 126 patients in each group were analyzed, no statistical significance was observed between milrinone and control group $(P=0.41$ for mortality and $P=0.31$ for morbidity).

Mortality: Two patients (1.6\%) died in milrinone group and four patients $(3.2 \%)$ died in control group, $P=0.41$ (Figure 6A).

Morbidity: These morbidities were bleeding, renal failure, and cerebrovascular accident. The most common morbidity was renal failure that occurred in eleven

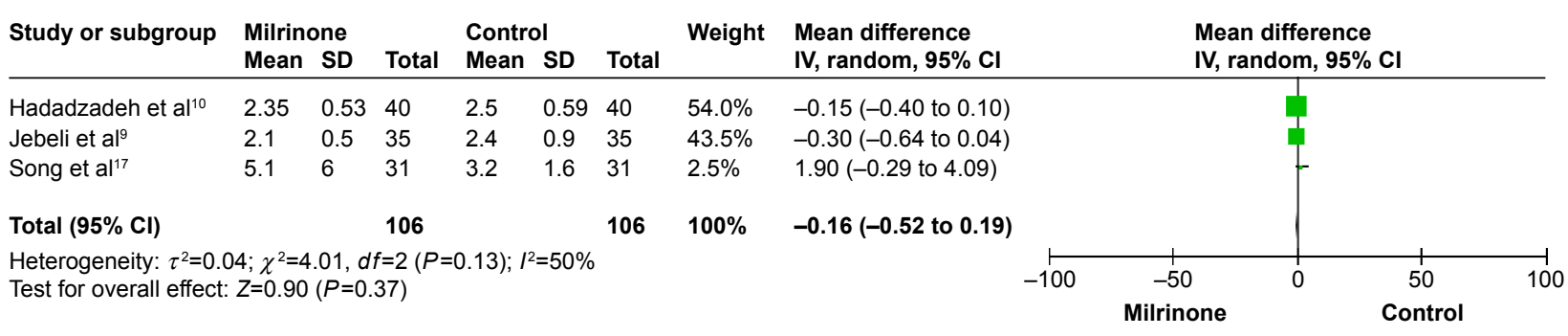

Figure 5 Forest plot comparing ICU stay between milrinone group and placebo/nesiritide group. Abbreviations: $\mathrm{Cl}$, confidence interval; IV, independent variable; ICU, intensive care unit. 


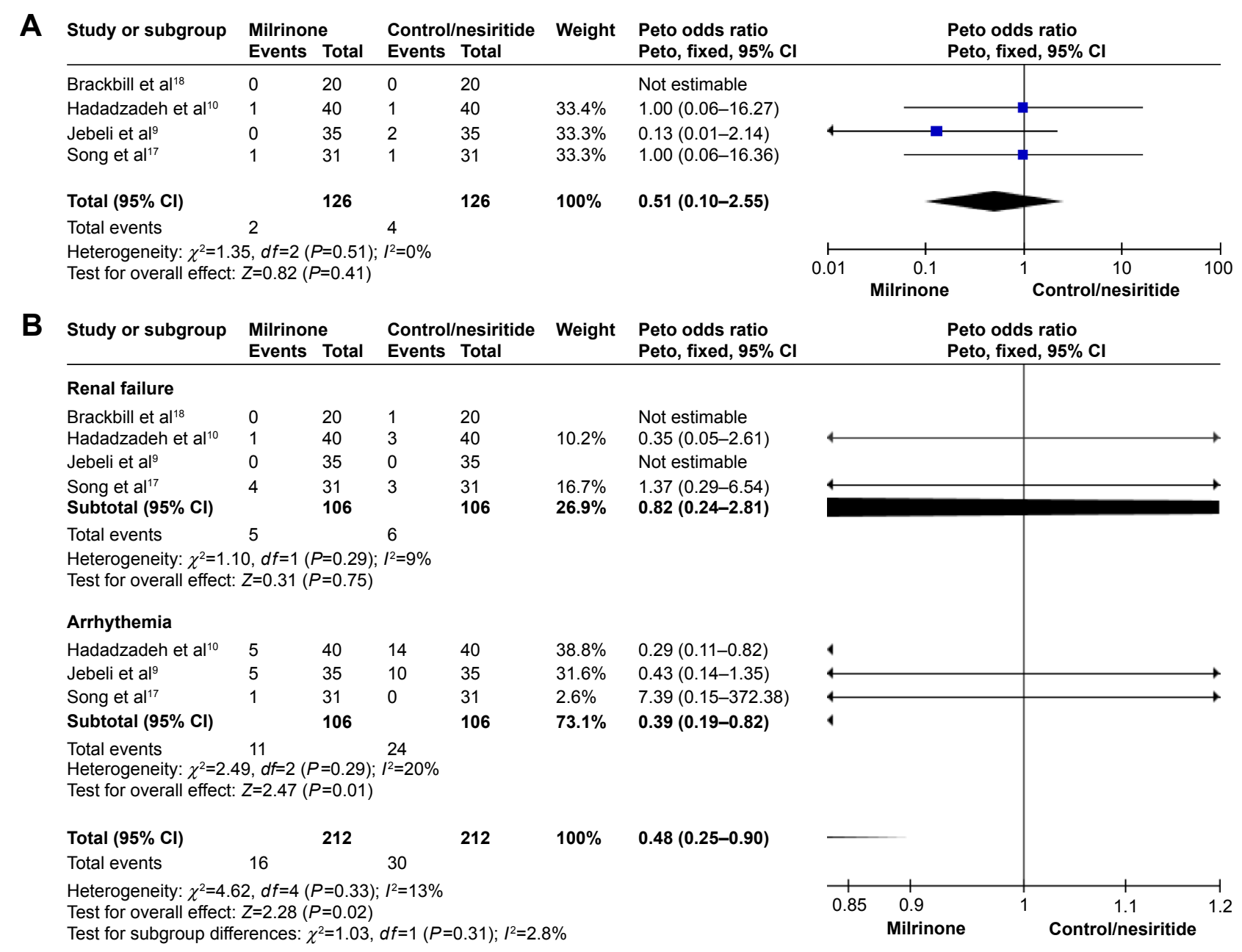

Figure 6 Forest plots comparing overall survival between milrinone group and placebo/nesiritide group in (A) mortality; (B) morbidity.

Abbreviations: $\mathrm{Cl}$, confidence interval; IV, independent variable.

out of 212 patients $(5.2 \%)$; five patients $(4.7 \%)$ in milrinone group and six patients $(5.7 \%)$ in the control group (Figure 6B).

\section{Discussion}

The results of this meta-analysis showed that administration of milrinone can protect against myocardial ischemia and myocardial infarction in patients undergoing CABG. Bailey et $\mathrm{al}^{11}$ and Jebeli et $\mathrm{al}^{9}$ studies showed the similar results. Hadadzadeh et $\mathrm{al}^{10}$ study and Gorodeski et $\mathrm{al}^{12}$ showed that there were no significant differences regarding incidence of myocardial ischemia and myocardial infarction in patients administered with milrinone. ${ }^{10}$ Even though it has a controversy, both Jebeli et $\mathrm{al}^{9}$ and Hadadzadeh et $\mathrm{al}^{10}$ studies revealed milrinone decreased creatine phosphokinase, creatine kinase-MB in CABG patients 4 and 24 hours after surgery. In the future, it may need multi-center studies with a large sample size to reach a solid conclusion.
Previous studies done by Kikura et al, ${ }^{4}$ Oztekin et al, ${ }^{13}$ and Yamaguchi et $\mathrm{al}^{14}$ indicated that milrinone decreased requirement of inotropic support after CABG surgery. Results of the meta-analysis study showed that there was no statistical significant difference regarding IABP requirement and inotropic support requirement between the two groups. However, the duration of inotropic requirement, duration of mechanical ventilation was lower in milrinone group, which was in accordance with the result of the study done by Levy et al. ${ }^{15}$ A study done by Konstam and Cody ${ }^{16}$ showed no significant difference in using IABP. This meta-analysis also found that it had no statistical difference in using of IABP or inotropic support requirement between both groups.

Song et $\mathrm{al}^{17}$ and Brackbill et al ${ }^{18}$ studies showed that there was no significant difference in mortality and morbidity between milrinone group and control group. Our analysis results also showed similar effect. However, those results are contradicted in with the study of Zangrillo et al, ${ }^{19}$ who 
reported that milrinone may increase mortality in patients undergoing cardiac surgery.

\section{Conclusion}

Milrinone decreased incidence of myocardial ischemia and infarction, decreased duration of inotropic support and mechanical ventilation for the patient after $\mathrm{CABG}$, but did not decrease the requirement of intra-aortic pump or inotropic support. In addition, milrinone did not improve the overall mortality/morbidity or decreased ICU stay duration. Therefore, administration of milrinone is beneficial and safe to patients undergoing CABG with LVEF overall even though it cannot improve mortality or morbidity.

\section{Disclosure}

The authors report no conflicts of interest in this work.

\section{References}

1. Möllhoff T, Schmidt C, Deng MC. Myocardial ischaemia in patients with impaired left ventricular function undergoing coronary artery bypass grafting - milrinone versus nifedipin. Eur J Anaesthesiol. 2002; 19(11):796-802.

2. Heringlake M, Wernerus M, Grunefeld J, et al. The metabolic and renal effects of adrenaline and milrinone in patients with myocardial dysfunction after coronary artery bypass grafting. Crit Care. 2007; 11(2):R51.

3. Abu-Omar Y, Taggart DP. The present status of off-pump coronary artery bypass grafting. Eur J Cardiothorac Surg. 2009;36(2):312-321.

4. Kikura M, Levy JH, Michelsen LG, et al. The effect of milrinone on hemodynamics and left ven-tricular function after emergence from cardiopulmonary bypass. Anesth Analg. 1997;85:16-22.

5. Monrad ES, Baim DS, Smith HS, Lanoue AS. Milrinone, dobutamine, and nitroprusside: comparative effects on hemodynamics and myocardial energetics in patients with severe congestive heart failure. Circulation. 1986;73:III 168-174.

6. Kwak YL, Oh YJ, Shinn HK, Yoo KJ, Kim SH, Hong YW. Haemodynamic effects of a milrinone infusion without a bolus in patients undergoing off-pump coronary artery bypass graft surgery. Anaesthesia. 2004; 59:324-331.
7. Doolan LA, Jones EF, Kalman J, et al. A placebo-controlled trial verifying the efficacy of milrinone in weaning high-risk patients from cardiopulmonary bypass. J Cardiothorac Vasc Anesth. 1997;11:37-41.

8. Lobato EB, Florete O Jr, Bingham HL. A single dose of milrinone facilitates separation from cardiopulmonary bypass in patients with preexisting left ventricular dysfunction. Br J Anaesth. 1998;81:782-784.

9. Jebeli M, Ghazinoor M, Mandegar MH, et al. Effect of milrinone on shortterm outcome of patients with myocardial dysfunction undergoing coronary artery bypass graft: a randomized controlled trial. Cardiol J. 2010; 17(1):73-78.

10. Hadadzadeh M, Hosseini SH, Mostafavi Pour Manshadi SM, Naderi N, Emami Meybodi M. Effect of milrinone on short term outcome of patients with myocardial dysfunction undergoing off-pump coronary artery bypass graft: a randomized clinical trial. Acta Med Iran. 2013;10:681-686.

11. Bailey JM, Levy JH, Kikura M, Szlam F, Hug CC Jr. Pharmacokinetics of intravenous milrinone in patients undergoing cardiac surgery. Anesthesiology. 1994;81(3):616-622.

12. Gorodeski EZ, Chu EC, Reese JR, Shishehbor MH, Hsich E, Starling RC. Prognosis on chronic dobutamine or milrinone infusions for stage D heart failure. Circ Heart Fail. 2009;2:320-324.

13. Oztekin I, Yazici S, Oztekin DS, Goksel O, Issever H, Canik S. Effects of low-dose milrinone on weaning from cardiopulmonary bypass and after in patients with mitral stenosis and pulmonary hypertension. Yakugaku Zasshi. 2007;127(2):375-383.

14. Yamaguchi A, Tanaka M, Naito K, Kimura C, Kobinata T, Okamura H. The efficacy of intravenous milrinone in left ventricular restoration. Ann Thorac Cardiovasc Surg. 2009;15(4):233-238.

15. Levy JH, Bailey JM, Deeb GM. Intravenous milrinone in cardiac surgery. Ann Thorac Surg. 2002;73(1):325-330.

16. Konstam MA, Cody RJ. Short-term use of intravenous milrinone for heart failure. Am J Cardiol. 1995;75(12):822-826.

17. Song JW, Jo YY, Jun NH, Kim HK, Kwak YL. The effect of milrinone on the intraoperative hemodynamics during off-pump coronary bypass surgery in patients with an elevated echocardiographic index of the ventricular filling pressure. Korean J Anesthesiol. 2011;60(3):185-191.

18. Brackbill ML, Stam MD, Schuller-Williams RV, Dhavle AA. Perioperative nesiritide versus milrinone in high-risk coronary artery bypass graft patients. Ann Pharmacother. 2007;41(3):427-432.

19. Zangrillo A, Biondi-Zoccai G, Ponschab M, et al. Milrinone and mortality in adult cardiac surgery: a meta-analysis. J Cardiothorac Vasc Anesth. 2012;26(1):70-77.
Drug Design, Development and Therapy

\section{Publish your work in this journal}

Drug Design, Development and Therapy is an international, peerreviewed open-access journal that spans the spectrum of drug design and development through to clinical applications. Clinical outcomes, patient safety, and programs for the development and effective, safe, and sustained use of medicines are a feature of the journal, which

\section{Dovepress}

has also been accepted for indexing on PubMed Central. The manuscript management system is completely online and includes a very quick and fair peer-review system, which is all easy to use. Visit http://www.dovepress.com/testimonials.php to read real quotes from published authors. 